Article

\title{
Design of the Cryogenic Bypass Line for the SIS100 Synchrotron
}

\author{
Artur Iluk ${ }^{1, *} \mathbb{C}$, Kazimierz Malcher ${ }^{1}$, Wiktor Słomski ${ }^{1}$, Maciej Chorowski ${ }^{2}$, \\ Jarosław Poliński ${ }^{2}$ (D) Thomas Eisel $^{3}$, Branislav Streicher ${ }^{3}$ and Peter Spiller ${ }^{3}$ \\ 1 Faculty of Mechanical Engineering, Wrocław University of Science and Technology, Łukasiewicza 7/9, \\ 50-371 Wrocław, Poland; kazimierz.malcher@pwr.edu.pl (K.M.); wiktor.slomski@pwr.edu.pl (W.S.) \\ 2 Faculty of Mechanical Power and Engineering, Wrocław University of Science and Technology, \\ Łukasiewicza 7/9, 50-371 Wrocław, Poland; maciej.chorowski@pwr.edu.pl (M.C.); \\ jaroslaw.polinski@pwr.edu.pl (J.P.) \\ 3 GSI Helmholtz Centre for Heavy Ion Research, 64291 Darmstadt, Germany; t.eisel@gsi.de (T.E.); \\ b.streicher@gsi.de (B.S.); p.spiller@gsi.de (P.S.) \\ * Correspondence: artur.iluk@pwr.edu.pl
}

Received: 4 November 2020; Accepted: 18 November 2020; Published: 23 November 2020

Featured Application: The design described in this paper was applied in the local cryogenics system of the SIS100 synchrotron, part of the Facility for Antiproton and Ion Research (FAIR) constructed in Darmstadt, Germany.

\begin{abstract}
This paper presents the selected aspects of a superconducting cryogenic bypass line (BPL) design, a part of the international Facility for Antiproton and Ion Research (FAIR) SIS100 cryogenic system, currently under construction in Darmstadt, Germany. Design, manufacturing, and installation of the superconducting cryogenic bypass line is a part of a Polish in-kind contribution to the FAIR project, realized by the Wroclaw University of Science and Technology. The BPL is dedicated to transferring liquid helium and AC electric current between SIS100 arc sections and superconducting quadrupole magnets located in warm straight sections of the synchrotron. A main innovative feature of the cryogenic bypass line is transferring the electric current and liquid helium in one vacuum vessel, while in other similar projects, namely, the Large Hadron Collider at CERN $(\mathrm{CH})$ or the Tevatron at FermiLab (USA), those functions are separated. The coexistence of superconducting busbars and liquid helium process pipes in one limited space, as well as numerous additional functional and technical requirements, was a source of the serious design and production challenges described in the paper, including two designs of the internal suspension system based on steel rods and aramid cables.
\end{abstract}

Keywords: superconducting cables; liquid helium; cryogenics; SIS100 synchrotron; Facility for Antiproton and Ion Research (FAIR)

\section{Introduction}

The Facility for Antiproton and Ion Research (FAIR) will be unique and one of the most complex international accelerator facilities for the research on antiprotons and ions. It is already under construction by an international collaboration at the GSI Helmholtzzentrum fur Schwerionenforschung near Darmstadt, Germany. Its core, a double-ring NbTi superconducting-technology-based SIS100 heavy-ion synchrotron, with a circumference of $1100 \mathrm{~m}$, will be associated with a complex system of cooler, storage rings and experimental setups (see Figure 1). This accelerator will deliver ion beams of unprecedented intensities and energies. Thus, intensive secondary beams can also be produced, providing antiprotons and exotic nuclei for groundbreaking experiments. 

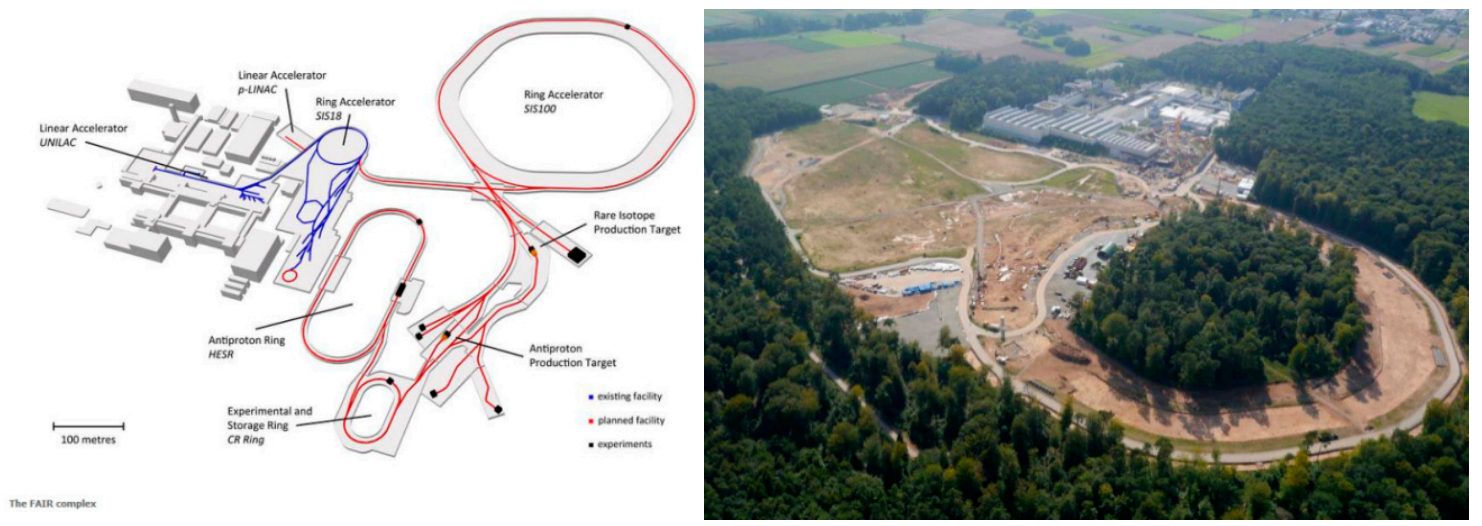

Figure 1. The layout of the Facility for Antiproton and Ion Research (FAIR; left) and a bird's eye view of the construction place (right).

A cryogenic system is required to cool the magnet system into a superconducting state. It distributes the cryogenic refrigerator's cooling capacity to the superconducting devices by supercritical or liquid helium. The design of exemplary supercritical helium cryogenic transfer lines is presented in [1,2], and an overview of the European X-ray Free Electron Laser (XFEL), with a similar cryogenic system, is provided in [3].

The cryogenic systems for the SIS100 synchrotron are comprised of a helium refrigerator, a distribution system, and the SIS100 local cryogenic system. The local cryogenics consist of the following:

- three feed boxes (FBs), each distributing subcooled liquid helium and electric current to two sectors;

- six current lead boxes (CLBs) connected to the feed boxes, providing electric current from normal conduction to the superconducting transfer system;

- $\quad$ six bypass lines (BPLs), where each distributes the cooling and electric current from the feed box to the magnets.

Design, manufacturing, and installation of all local cryogenic components of SIS100 is a Polish in-kind contribution to the FAIR project, realized by Wroclaw University of Science and Technology. The in-kind contribution is coordinated by a Polish shareholder-the Jagiellonian University in Krakow. In the paper, several technical solutions were presented, including two types of internal floating-suspension system based on stainless steel rods and aramid cables. The aramid cable suspension has been previously used in cryogenics applications in [4-7]; a trial of the application in SIS100 BPL was presented.

\section{Bypass Line Design Requirements}

The synchrotron SIS100 is divided into six sectors (see Figure 2), each composed of an arc section containing a number of superconducting magnets and a straight section containing three superconducting quadrupole magnets (QDMs). Between the QDMs of the straight sections, warm accelerating components are located. Thus, electric current and liquid helium need to be bypassed at the warm components.

The single bypass line consists of five process pipes and four pairs of superconducting busbars. The SIS100 ring contains six bypass lines with a length of about $50 \mathrm{~m}$ each, connected hydraulically and electrically to the magnets. It is designed to bypass warm gaps between magnets on the straight sections of SIS100 and to provide electric current and liquid helium to arcs sections and quadrupole magnets. The total length of the bypass lines is equal to about $300 \mathrm{~m}$. 


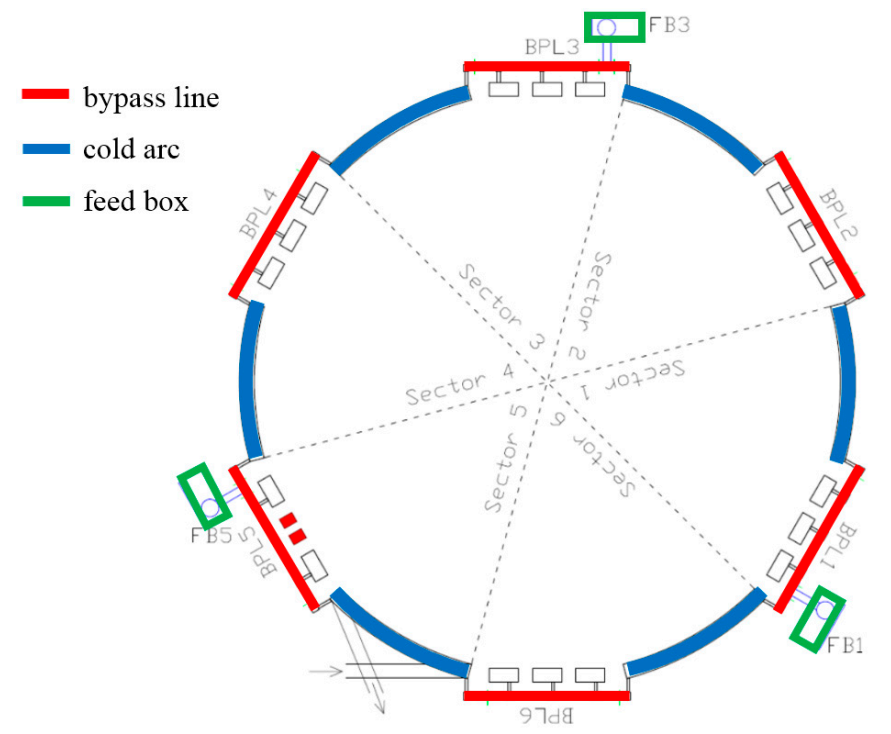

Figure 2. Schematic representation of the SIS100 accelerator showing the six bypass line (BPL) sections. The cold arc sections and BPL sections are for clarity and are not shown in proportion to each other. FB1, FB3, FB5-feed boxes.

Electric power and liquid helium are provided to sections of the bypass line by short feed-in lines from three feed boxes, one per two sectors. The electric power is transferred from feed boxes by the $\mathrm{NbTi}$ superconducting busbars, cooled by a two-phase liquid-vapor mixture of helium. The required helium mass flow adjustment is done by isenthalpic throttling in a capillary [8]. A cross-section of the $\mathrm{NbTi}$ superconductor is shown in Figure 3. The outer superconducting wires are cooled by the helium flowing through the central CuNi tube. Details of the cable structure are given in [9].



Figure 3. Cross section of the NbTi superconducting cable for the busbars of the SIS100 synchrotron [10].

The main innovative feature of the cryogenic bypass line is transferring the electrical current and helium in a single vacuum insulation vessel. In existing transfer systems, those functions are usually separated. The standard transfer line contains only hydraulic process pipes [11]. The coexistence of busbars and helium process pipes in one vacuum vessel allows the reduction of the number and overall size of the required vacuum vessels, which is very important in the limited space of the SIS100 
tunnel. The space restrictions are more pronounced in the second accelerator, SIS300, which is planned to be located in the same tunnel, above SIS100 [12].

The magnets of SIS100 will be ramped up with an electrical current of up to $13.2 \mathrm{kA}$ and a frequency of up to $1 \mathrm{~Hz}$. Four busbar pairs supply the electrical current independently to the different magnet circuits, all of which need to be integrated in the BPL. Due to the significant total BPL length of $300 \mathrm{~m}$ and usage in SIS100 of the independently controlled fast-ramping magnets, the presence of the cross-talk between busbars pairs and parasitic capacities can affect the quality of the magnetic fields $[13,14]$. The layout of the BPL cross-section was determined by maximizing the distance between the busbars pairs.

One of the requirements for the magnetic system is the extremely high precision of the magnet alignment on the whole 1100-m-long ring of the SIS100. The high precision of the magnet's cold structure position must not be affected by pressure forces or by thermal contraction stresses from the BPL. Therefore, the next significant feature of the BPL is to provide helium at a pressure of up to 18 bar(a) to the magnets without exerting any significant forces on the magnet's cold structure. Simultaneously, as the magnets will be installed and positioned after BPL installation, the BPL design should allow for the adjustment of the magnet cryostats within a range of $\pm 15 \mathrm{~mm}$ in any direction.

The next feature of the BPL is the partitioning of the SIS100 vacuum space. In order to avoid the risk of catastrophic loss of the insulation vacuum in the whole SIS100 ring by a single leak, the SIS100 vacuum space was divided into fifteen sections separated by vacuum barriers, which are located in the bypass lines. In the case of a helium leak in any vacuum section, the BPL vacuum vessel might cool down by approximately $100 \mathrm{~K}$ and shrink due to thermal contraction. The vacuum barriers will be loaded with the pressure forces of about $20 \mathrm{kN}$ each, which have to be entirely captured by BPL without transfer of the forces to the magnet's cold structures. Process pipes in the SIS100 ring are protected against excessive pressure build-up by the safety valves, also located in the bypass lines.

For those reasons, the bypass line has to be designed to be flexible, allowing free movement of the magnet during its adjustment and simultaneously capturing all pressure forces and thermal contractions. The requirement of zero-force exerted on the magnets means that the bypass line needs to be designed with a very limited set of external fixed supports. The design of such a structure is challenging from a mechanical point of view.

The general layout of the SIS100 bypass line is shown in Figure 4. The specification of the design parameters of the process pipes is presented in Table 1. The support system is divided into three parts:

- external support of the vacuum vessel;

- $\quad$ supports of the thermal shield inside the vacuum vessel;

- $\quad$ supports of process pipes and superconducting busbars inside the thermal shield.

The parameters of the process pipes-temperatures, operating and design pressures-are presented in Table 1 . The busbar system is hydraulically connected between He-supply magnet pipes (A1) and He-return magnet pipes (B). The operating temperature of the superconducting busbars (BBs) is $4.5 \mathrm{~K}$. 


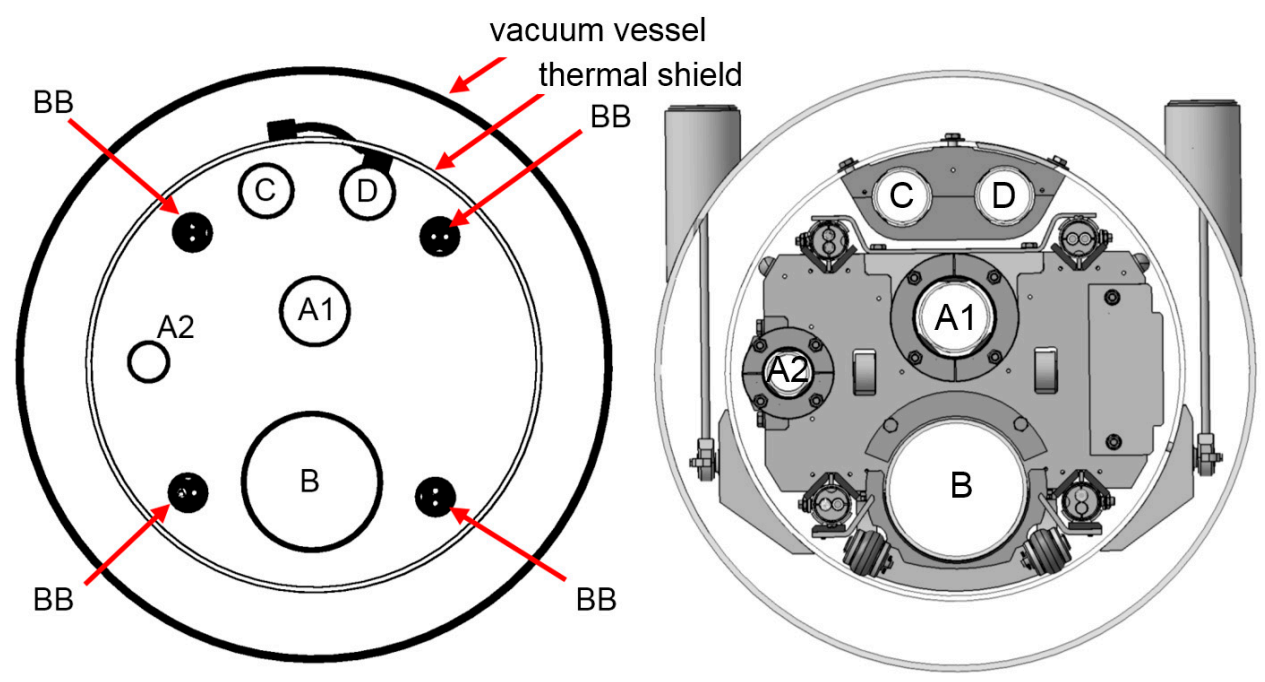

Figure 4. General cross-sectional layout of the SIS100 bypass line: without supports (left); with supports (right). A1, A2, B, C, D—helium process pipes, BB-superconducting busbars.

Table 1. The specification of the design and operating parameters of the process pipes.

\begin{tabular}{ccccccc}
\hline Pipe & Headers \& Shells & $\begin{array}{c}\text { O. Diameter \& }_{\text {Thickness }^{\circ}}\left[\begin{array}{c}\text { Operating } \\
\text { [mm] }\end{array}\right. \\
\text { Temperature } \\
{[\text { [K] }}\end{array}$ & $\begin{array}{c}\text { Operating } \\
\text { Pressure } \\
{[\text { bar(a)] }}\end{array}$ & $\begin{array}{c}\text { Design } \\
\text { Pressure } \\
{[\text { bar(a)] }}\end{array}$ & $\begin{array}{c}\text { Test } \\
\text { Pressure } \\
{[\text { bar(a)] }}\end{array}$ \\
\hline A2 & $\begin{array}{c}\text { He supply vacuum } \\
\text { chamber (VC) }\end{array}$ & $32 \times 2$ & 4.5 & 3 & 20 & 28.6 \\
\hline B & $\begin{array}{c}\text { He return } \\
\text { magnets + VC }\end{array}$ & $108 \times 3$ & 4.3 & 1.1 & 20 & 28.6 \\
\hline C & He supply shield & $42.4 \times 2$ & 50 & 18 & 20 & 28.6 \\
\hline D & He return shield & $42.4 \times 2$ & 80 & 17 & 20 & 28.6 \\
\hline
\end{tabular}

\section{Mechanical Design of BPL}

In the vacuum vessel of BPL, there is no separated fixed support in the vertical direction; the only fixed supports are the magnet flanges. The vacuum vessel is elastically supported in the vertical direction by long-stroke spring supports. After adjustment of the spring forces, the supports carry the full weight of the BPL in the desired vertical position. The vacuum vessel is attached to the magnet flanges by corrugated compensators (Figure 5). These compensators are used only to compensate for the misalignment of the flanges of BPL with flanges of the magnet during the assembly process. After adjustment and flange mounting, the compensators are fixed by four rods, making the connection of BPL modules with the magnets rigid.

As in standard transfer line designs, two additional axial compensators per module are used to increase BPL flexibility and compensate for a thermal contraction in the case of helium leakage.

Axial supports are located at the ends of each BPL to carry the full axial pressure forces acting on the vacuum vessel. The axial supports are separated from magnet axial compensators in order to avoid transferring pressure forces onto the magnet flange.

Liquid helium, distributed along the BPL, has a temperature of $4.5 \mathrm{~K}$. In order to avoid significant heat loads from the vacuum vessel, liquid helium process pipes are thermally separated by high-insulation vacuum and multilayer insulation (MLI). The MLI covers process pipe surfaces and all other cold components in vacuum space. In addition, the $4.5 \mathrm{~K}$ process pipes are surrounded by a thermal shield (TS) that is kept at a $60-80 \mathrm{~K}$ temperature level. This allows the interception of a large amount of heat that would be transferred from the vacuum vessel directly to the liquid helium process 
pipes. The thermal shield is also cooled with the use of cold, high-pressure helium that circulates in the supply and return lines of the TS circuit. As the thermal shield is made of aluminum, which, by high thermal conductivity, ensures homogenous temperature distribution along the shield, it is thermally coupled with the shield's return process pipe by flexible braids made of copper. Such design decouples the stresses due to the difference in the stainless steel and aluminum thermal contraction, especially during cool-down and warm-up.

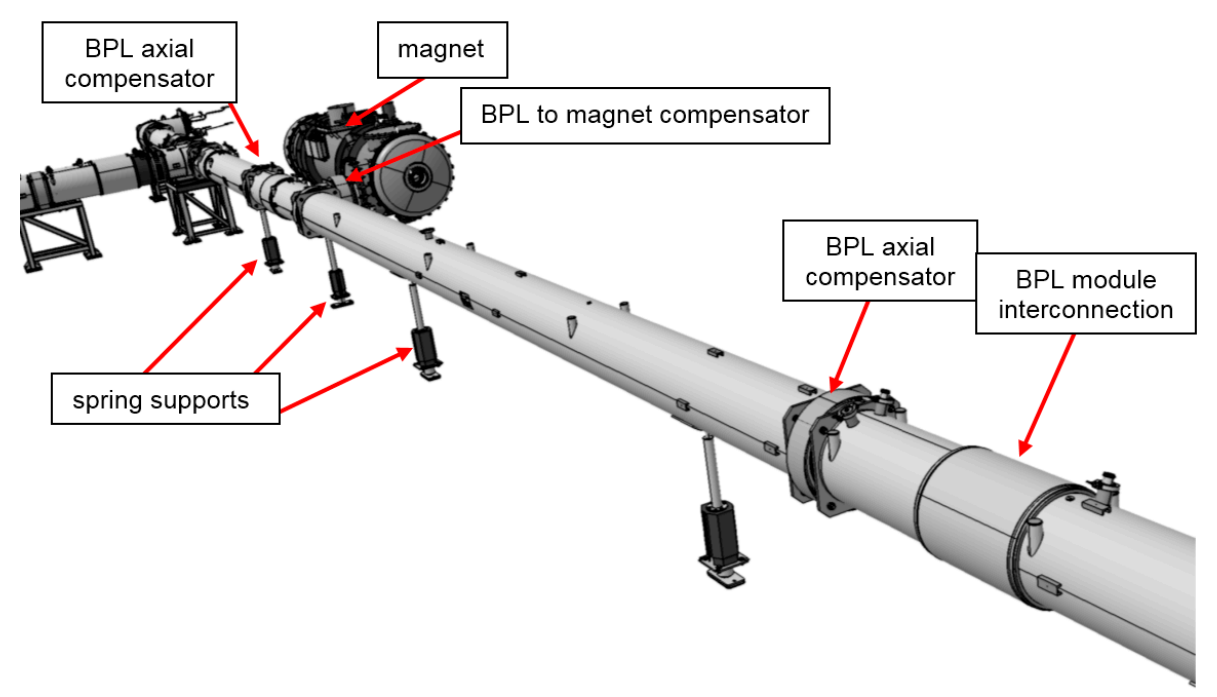

Figure 5. Suspension and compensation of the BPL vacuum vessel.

The design of the bypass line uses an innovative concept of the floating cold mass (Figure 6). Its principle is to remove the internal supports of the BPL cold mass and suspend the entire interior on swinging links. Free movement of the BPL cold mass significantly reduces the forces exerted on the magnets and makes it easier to maintain their stable position relative to the beam axis. Simultaneously, in case of displacement of the cold mass, gravity provides a small centering reaction.

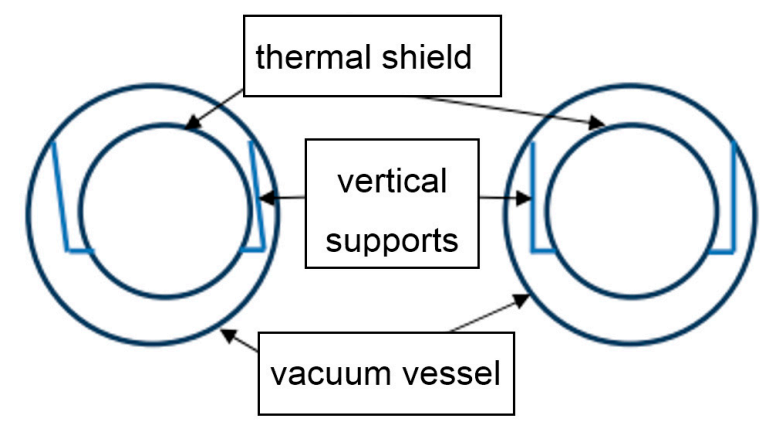

Figure 6. The floating support system of the thermal shield: displaced thermal shield (left); centered thermal shield (right). The lateral displacement is exaggerated for clarity.

Due to the floating support, the cold structure of the bypass line is able to contract toward the thermal contraction centers of the magnets without compensation elements between the magnet and the BPL.

The suspension of the thermal shield was designed in two versions. The first was based on aramid fiber cords (Kevlar 49) with a diameter of $3 \mathrm{~mm}$ (Figures 7 and 8). The single cord, in the form of a closed-loop, supports the thermal shield tube by four thermally insulating spacers made of G11 glass fiber laminate to avoid direct thermal contact of the cord and the multilayer insulation (MLI) of the thermal shield. The spacers simultaneously provide $10 \mathrm{~mm}$ space for the MLI to avoid its compression. The weight of the thermal shield and all the cold mass inside the thermal shield is 
distributed among all four spacers and reaction forces are applied to the thermal shield only in the radial direction. The vertical adjustment, shown in Figure $7 \mathrm{a}$, can be used to balance the forces in all the aramid cords along the BPL module during the manufacturing stage.

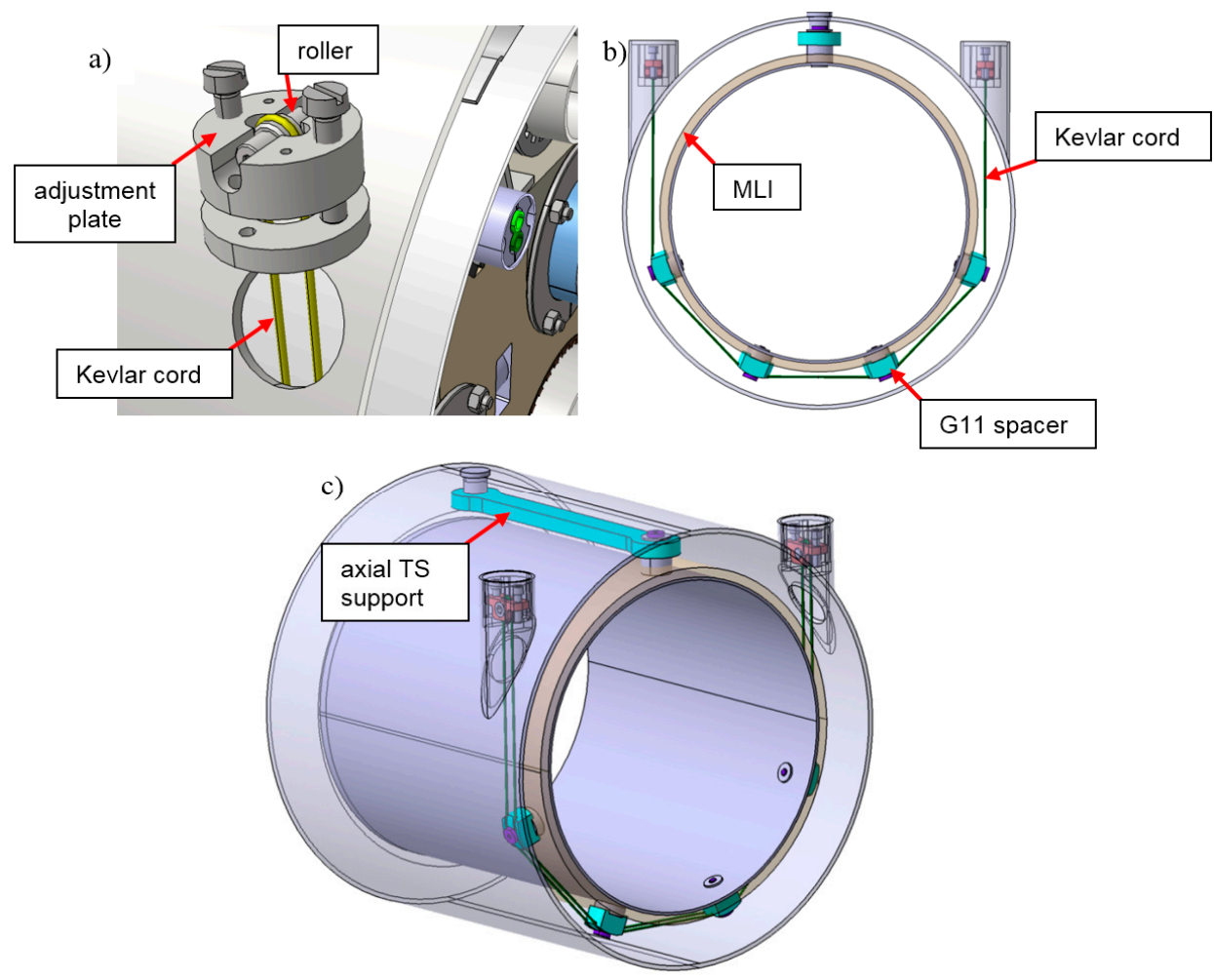

Figure 7. Suspension of the thermal shield on aramid (Kevlar 49) cords: (a) vertical adjustment of the single loop; (b) location of G11 spacers on the circumference of the thermal shield with multilayer insulation (MLI); (c) G11 axial support of the thermal shield segment.

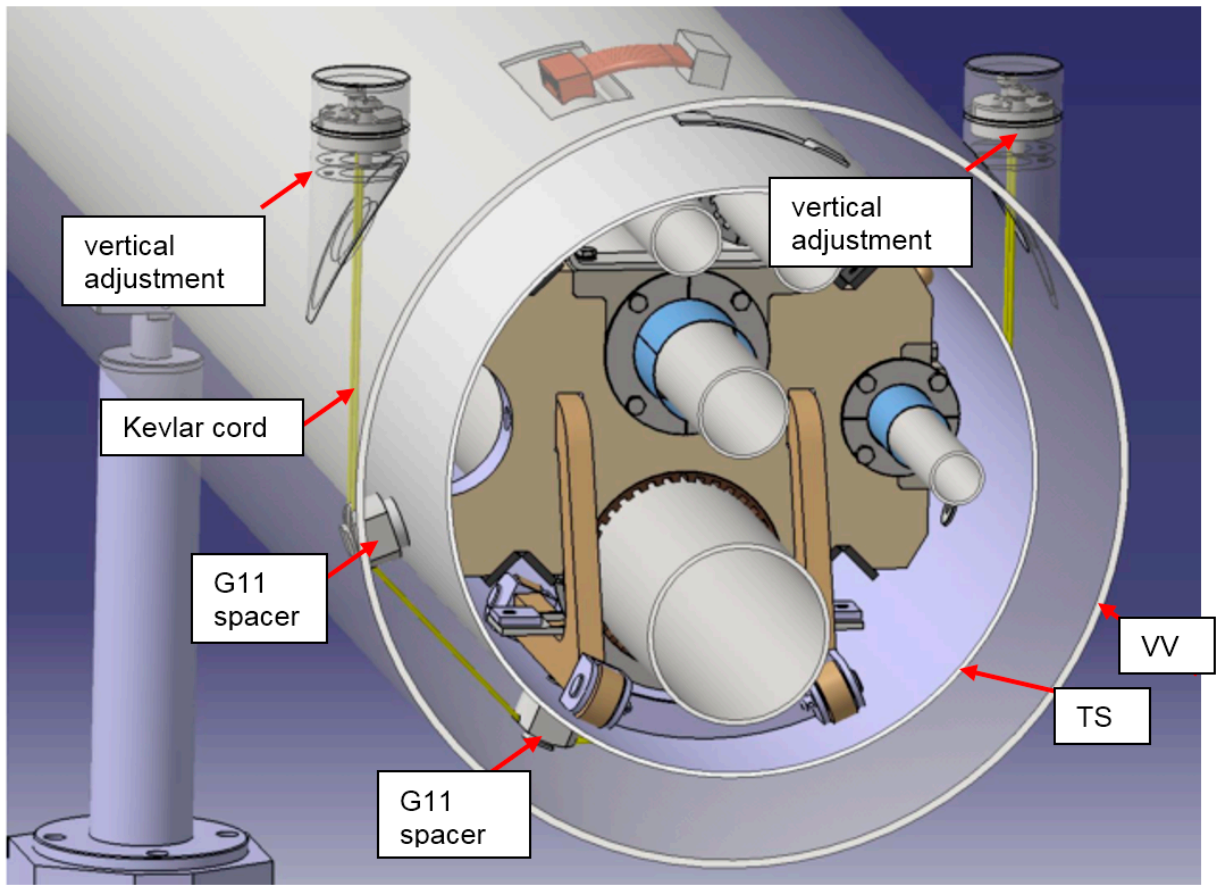

Figure 8. Suspension of the thermal shield (aramid fiber cable version) with interior details. 
Both upper ends of the loop pass through the holes in the vacuum vessel and are supported on rollers with an adjustment range in a vertical direction. The rollers provide the ability of self-balance of the forces in all lines of the aramid cord. Loops are located along the pipe, with a $2.7 \mathrm{~m}$ average distance between them. The thermal shield is divided into approximately 6 -m-long segments; the axial position of each segment is fixed with the use of a G11 axial support arm (shown in Figure 7c).

The second concept of the thermal shield suspension is based on the stainless-steel rods instead of aramid cords (Figure 9). A pair of steel rods are attached to the thermal shield by hinges. Because of the significant force and bending moment acting on the TS, the area of connection to TS is strengthened. Upper ends of the rods are supported by the vacuum vessels with the possibility of vertical adjustment. In Figure 10, the cold mass suspension system in the area of magnet connection is shown.

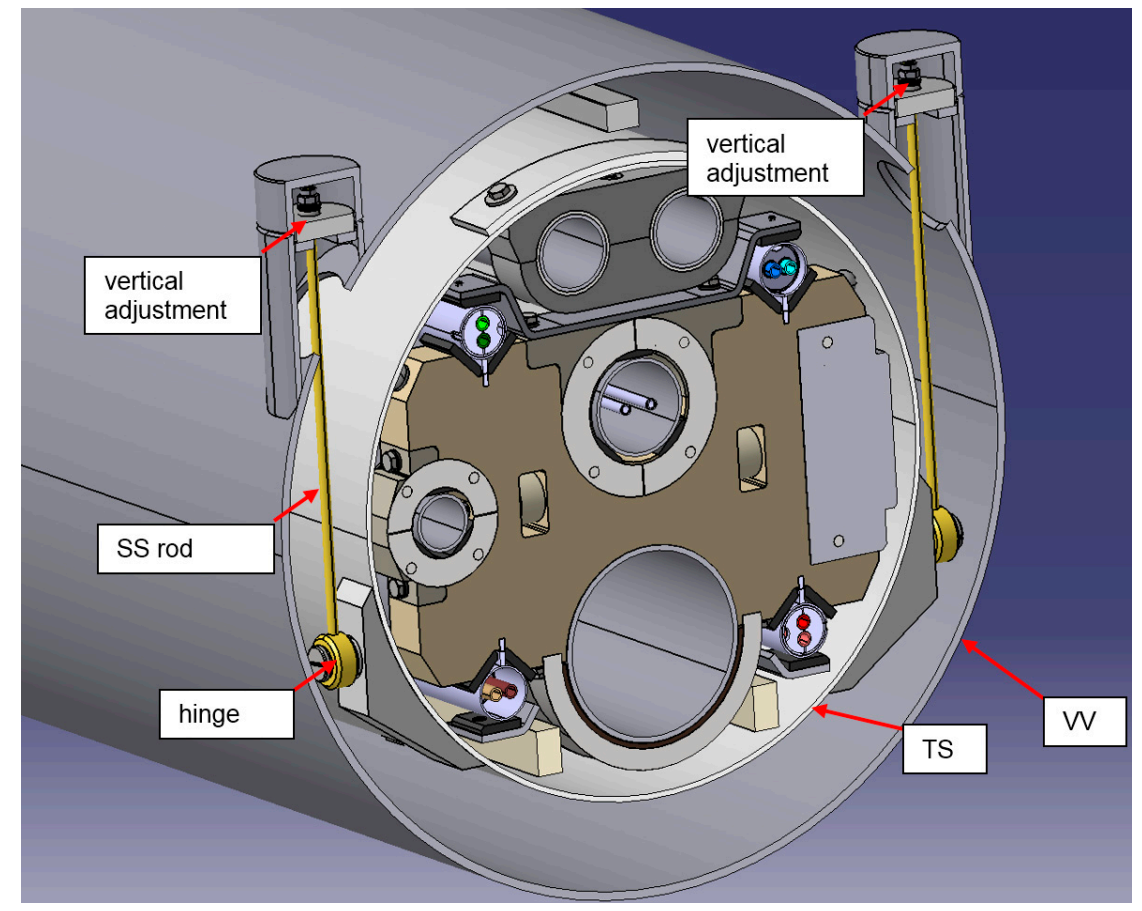

Figure 9. Suspension of the thermal shield (stainless steel rod version).

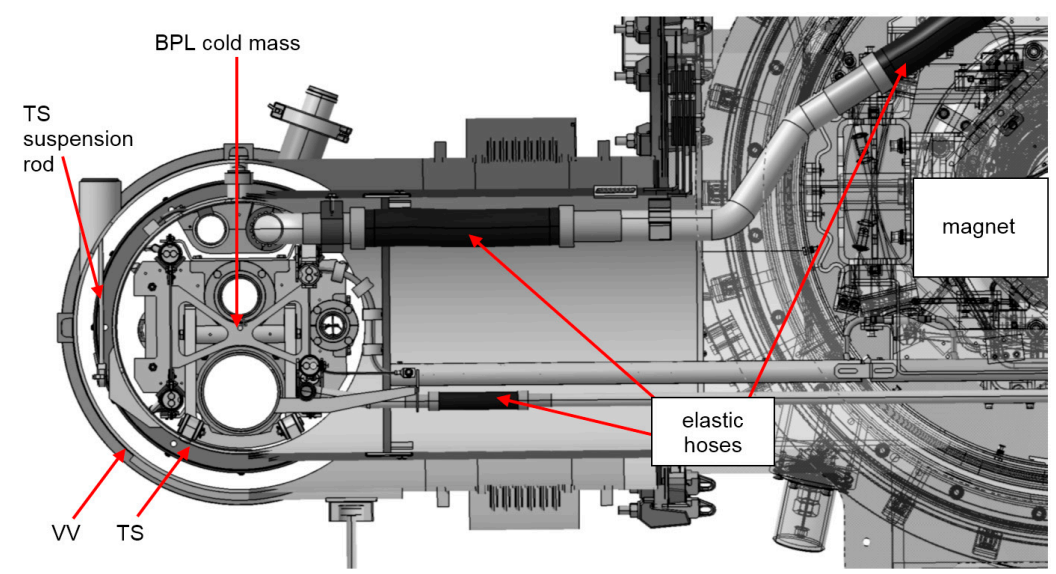

Figure 10. Connection of the BPL cold mass to the magnet in a lateral direction by elastic hoses on process pipes.

Aramid cord suspension has several advantages compared to steel rod suspension. The ratio of strength to thermal conductivity of Kevlar is much higher than for stainless steel (Figure 11). The thermal conductivity of Kevlar $49[15,16]$ at the $50-300 \mathrm{~K}$ temperature range is approximately $80 \%$ 
lower than the thermal conductivity of stainless steel. The summary cross-section of the pair of aramid strings is twice smaller than the cross-section of the steel rod because of the higher strength of Kevlar.

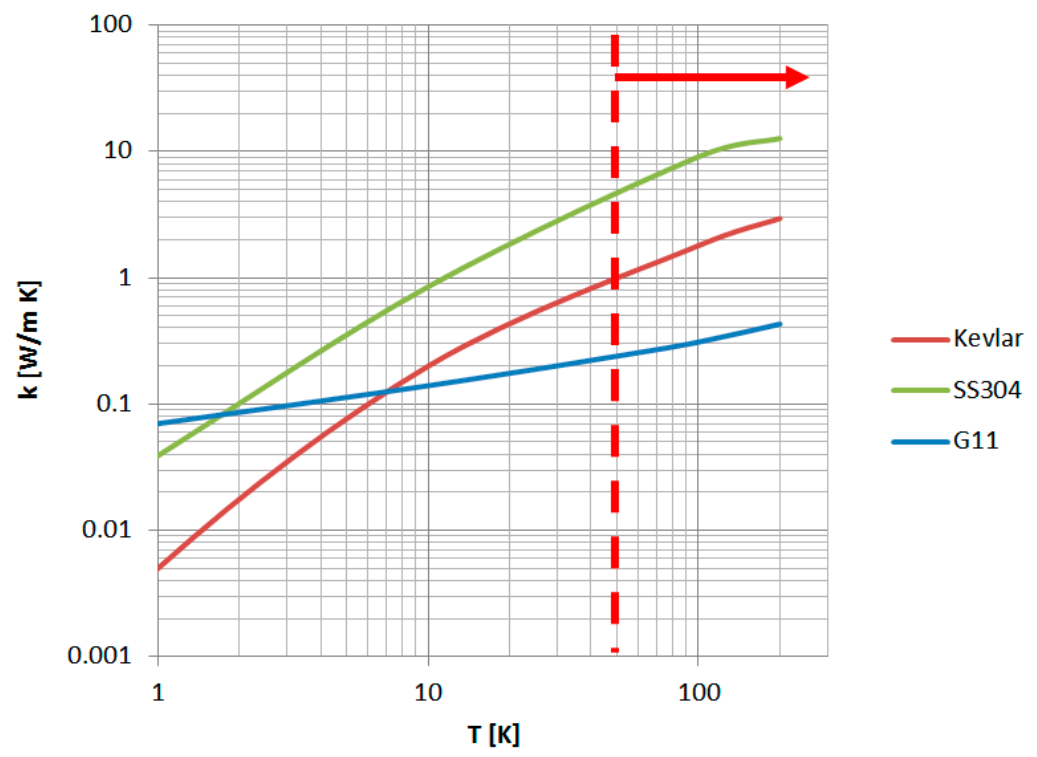

Figure 11. Thermal conductivity of various materials used for cryogenic support and range on thermal shield (TS) support temperatures. Red line shows the operational temperature range.

In the case of aramid cords, the mechanical load is applied to the TS as a force in the radial direction, distributed among four G11 spacers. No bending moment is applied, and forces can be carried directly by the TS pipe. The loop suspension is also a simpler and cheaper solution.

The only disadvantage of Kevlar cord suspension is the risk of creeping during long-term operation. Even if the load of the aramid cord is well below the yield strength, the plastic material can suffer mechanical creep, a slow increase of plastic deformation that depends on the load, temperature, and time. As a result, the deformation can exceed mechanical tolerances or even cause the loss of mechanical stability.

While aramid cord suspension has been used in some cryogenic applications-SAFIRE, CUORE, MINERvA [4,5], there are still very limited data about the long-term use of aramid fibers in cryogenic applications. In [6], a single Kevlar-braided loop was considered to be a good candidate for internal cryostat suspension. In [7], the long-term mechanical creep of Kevlar 49 fiber at a temperature of $4.2 \mathrm{~K}$ was investigated. The fiber $(0.5 \mathrm{~mm}$ in diameter) was loaded with a mass of $2.7 \mathrm{~kg}$ for a period of 8 months. A $0.004 \%$ creep strain was reported. The creep was very limited, but this was measured in a period that was much shorter than the 30 years of planned operation of the SIS100 accelerator and at a temperature of $4.2 \mathrm{~K}$ instead of the $80 \mathrm{~K}$ of the BPL thermal shield.

The aramid braided-rope designed for the suspension of the SIS100 BPL would have to remain functional for the 30 years of SIS100 operation, with no possibility of exchanging damaged elements of the suspension system. Because of the lack of experimental data for the long-term creep behavior of aramid cords, the second option of steel rod suspension is used.

The process pipes are supported inside the thermal shield by G11 support plates. All the plates are clamped onto return pipe B (outer diameter $108 \mathrm{~mm}$ ). The first plate on the upstream end of the module is a fixed support plate; the other plates are sliding ones. It allows the relative axial movements of the process pipes. At the downstream end of the module, there are axial bellows to compensate for the thermal contraction of the process pipes.

The G11 support plates are supported inside the TS on G11 roller arms equipped with four G11 wheels. The wheels provide sliding support for the G11 plates (Figure 12). 


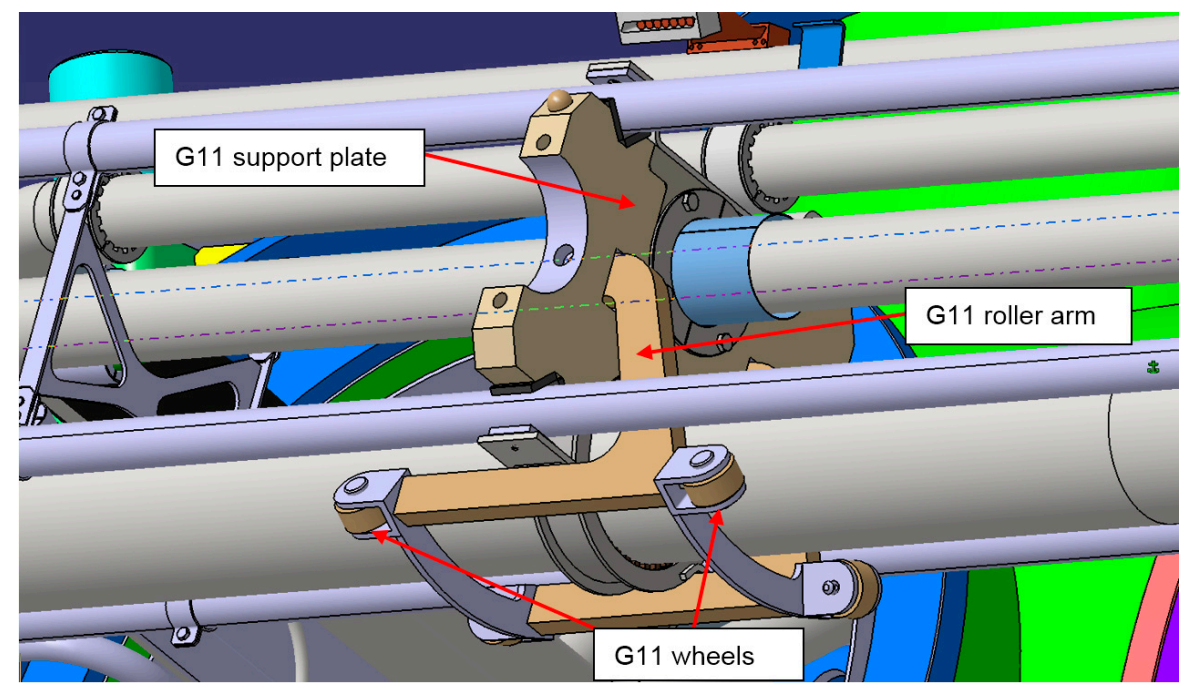

Figure 12. PP The sliding support of process pipes, G11 roller arm, and G11 wheels.

Busbar pairs are clamped to carry the significant Lorenz forces due to the high electrical current transferred by each busbar pair. These forces act in a repelling manner. The equidistant and short clamping avoids plastic deformation of the superconducting cable. In order to achieve a high-quality magnetic field, the electromagnetic cross-talk between the four busbar pairs has to be minimized [12,17] by a stable relative position and, especially, the orientation of the busbar pairs.

The clamped busbar pair is slid into a stainless steel support pipe, providing a stiffness sufficient to keep the BB pair in the correct position with respect to the process pipes and the thermal shield (Figure 13). The support pipes are supported in the G11 support plates.

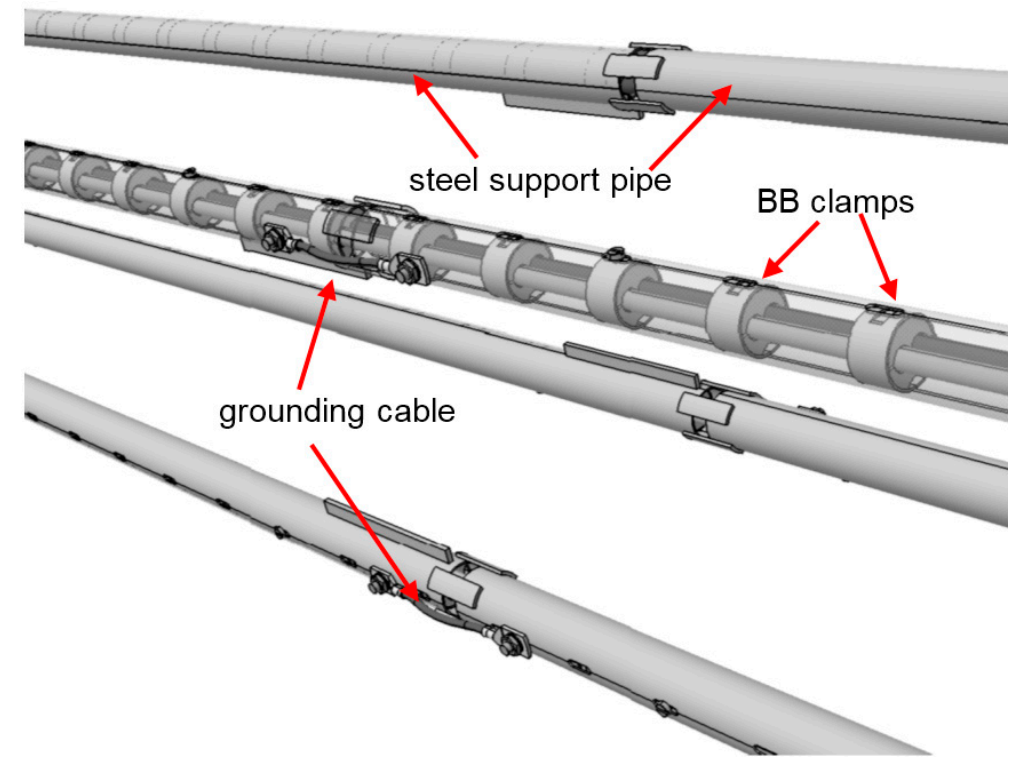

Figure 13. Segments of the busbar (BB) support system.

During the thermal shrink of the busbars, the clamps slide inside to avoid the axial stresses of the busbars. The support pipes are electrically connected by grounding cables.

At the downstream end of the module, the thermal compensation loops are placed on the busbar pairs. The loop compensates for up to $40 \mathrm{~mm}$ of the thermal contraction of the busbars (Figure 14). 


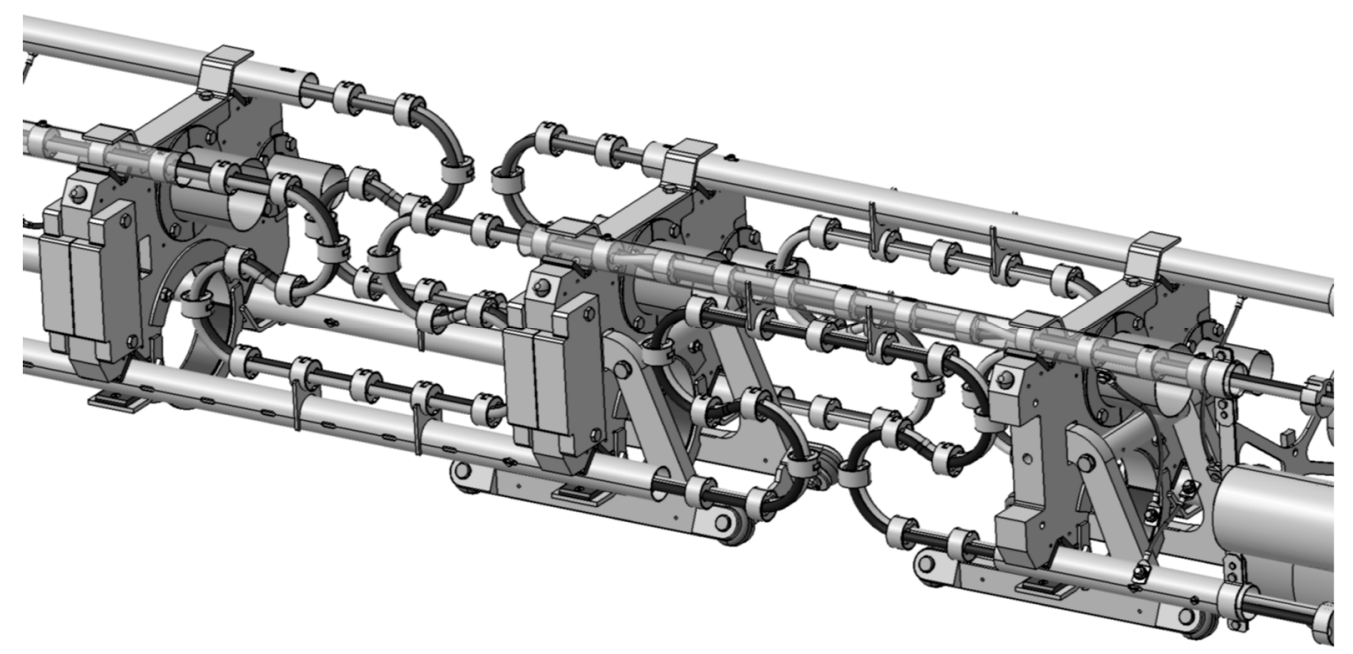

Figure 14. Thermal compensation loops on the busbar pairs on the support plates.

\section{Delivery and Tests Results}

The first module of the SIS100 cryogenic bypass line (Figure 15) was delivered by Wroclaw University of Science and Technology to GSI in the middle of 2016. This module is being used as part of the SIS100 String Test Facility (STF) to verify the operation of a short chain of SIS100 superconducting magnets. The first series module connects the STF feed box to the tested short chain of magnets.
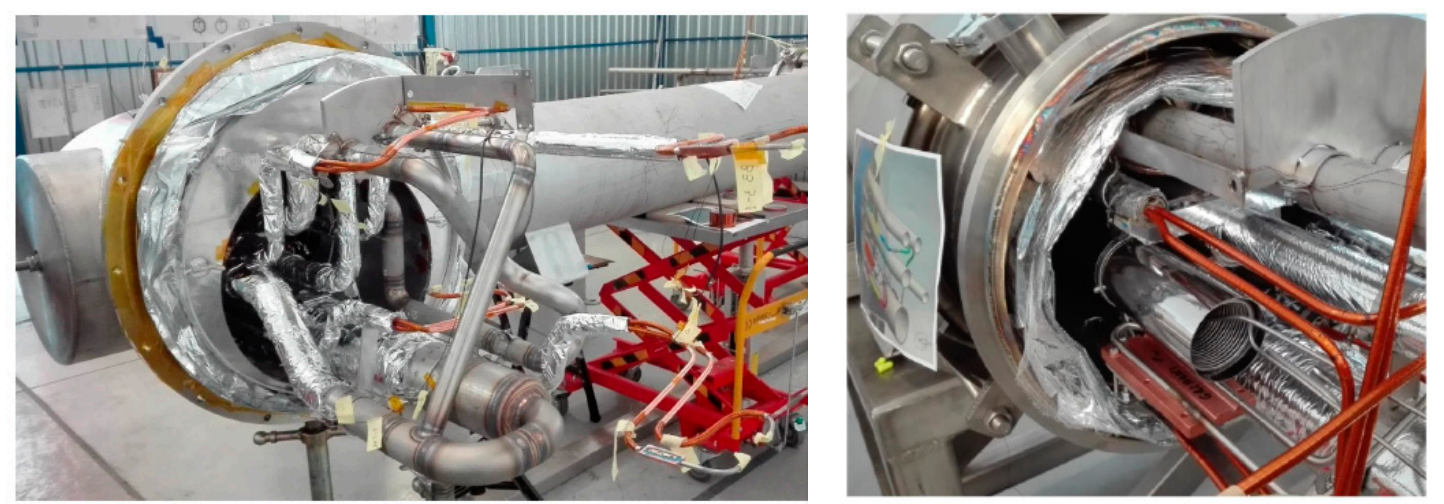

Figure 15. Preparation of the first BPL module for testing at GSI, Darmstadt.

Before the magnets' short string verification test, the first SIS100 BPL module of the series was tested from the view of thermodynamics (heat losses) and electric performance. Figure 16 presents an example of heat-load measurement. The heat in-leak to the $4.5 \mathrm{~K}$ circuit, including the busbar system, was measured in two states:

(a) the static condition, when the busbar system was not powered and all heat losses were transferred through the thermal insulation and supports;

(b) the transient condition, when superconducting busbars were powered with AC current. 

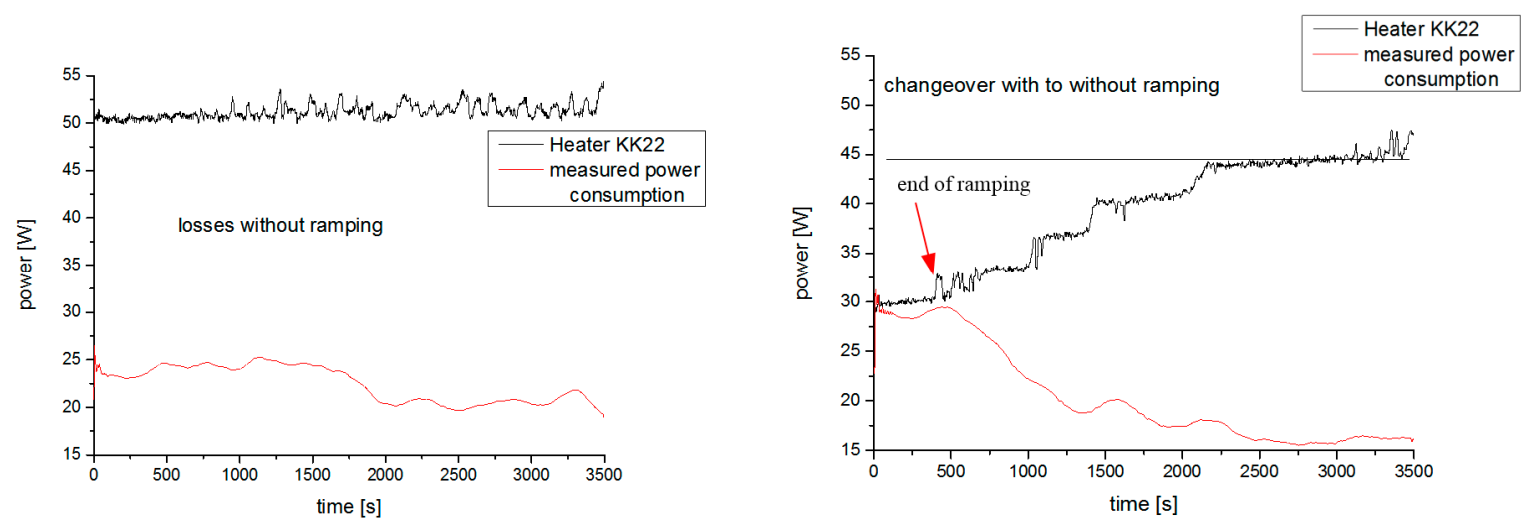

Figure 16. The measured heat losses [W] in the first SIS100 BPL series module, measured at a temperature of $4.5 \mathrm{~K}$ for a static condition (left) and for a transition from a dynamic load (ramping) of superconducting busbars to a static condition (right).

Detailed test results will be the subject of a separate article.

The first serial BPL linear module 1S42YP was manufactured, tested at the manufacturer's premises, and delivered to the FAIR project in October 2020. A view of the module prepared for the site acceptance tests (SAT) is presented in Figure 17.

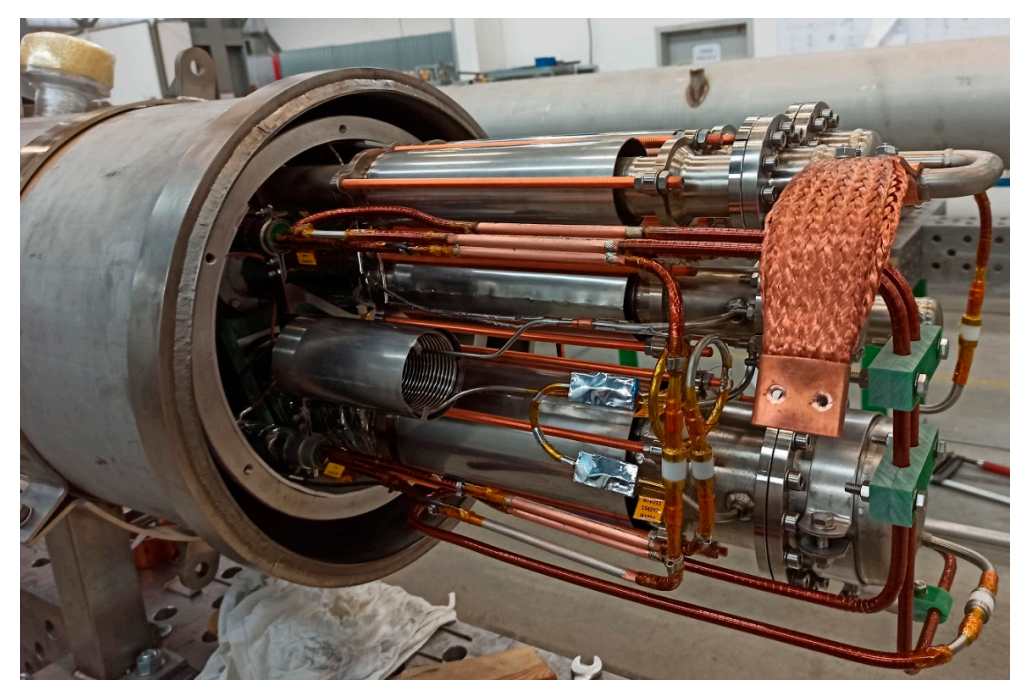

Figure 17. The module 1S42YP prepared for a SAT test.

In the next stage, one of the three feed boxes for liquid helium and electric power supply for the SIS100 ring will be designed and delivered. These components are to be tested in the Test String prior to the installation of a complete set of six bypass lines in the SIS100 tunnel.

\section{Conclusions}

The article presents selected aspects of the design of a superconducting bypass line that operates at cryogenic temperatures. The innovative solutions are implemented in the final design of the BPL to allow a simultaneous transfer of liquid helium and ramped electrical current to superconducting magnets.

The special external and internal support system of all elements of the bypass line was designed to minimize the forces exerted on the precisely positioned superconducting magnets of the SIS100 ring. Two versions of the cold-mass floating suspension system were designed-on stainless steel rods and on aramid ropes. The stainless steel version was selected due to the lack of evidence of the long-term creep behavior of aramid ropes. An effective and relatively simple support and clamp system 
for over $2 \mathrm{~km}$ of superconducting $\mathrm{NbTi}$ type cables was created, providing stable busbar position and orientation.

The first of series (FoS) module of the cryogenic bypass line for the SIS100 accelerator has been delivered to GSI and successfully tested. The first serial linear module of the cryogenic bypass line was manufactured in Wrocław, Poland, and delivered to the FAIR facility in October 2020.

Author Contributions: Conceptualization, A.I. and K.M.; methodology, A.I., J.P. and T.E.; validation T.E. and B.S.; investigation, A.I. and W.S.; writing-original draft preparation, A.I.; writing-review and editing, M.C., T.E. and J.P.; visualization, A.I., K.M. and W.S.; supervision, M.C. and P.S.; funding acquisition, M.C. and P.S. All authors have read and agreed to the published version of the manuscript.

Funding: The cryogenic equipment described in the publication was made for the FAIR GmbH Center as part of the in-kind contribution of the Polish Shareholder in FAIR GmbH (Jagiellonian University), declared by the Polish government at the international FAIR Convention and financed from the state budget.

Conflicts of Interest: The authors declare no conflict of interest. The funders had no role in the design of the study; in the collection, analyses, or interpretation of data; in the writing of the manuscript, or in the decision to publish the results.

\section{References}

1. Pławski, E.; Sekutowicz, J.; Grabowski, W.; Kosiński, K.; Lorkiewicz, J.; Wojciechowski, M.; Gołębiewski, Z.; Meissner, K.; Wrochna, G.; Chołuj-Dziewiecka, O.; et al. Polish in-kind contribution to European X-ray Free Electron Laser (XFEL): Status in spring 2013. Synchrotron Radiat. Nat. Sci. 2013, 12, 1-5.

2. Rusiński, E.; Chorowski, M.; Iluk, A.; Fydrych, J.; Malcher, K. Selected aspects related to the calculations and design of a cryogenic transfer line. Arch. Civ. Mech. Eng. 2014, 14, 231-241. [CrossRef]

3. Decking, W.; Abeghyan, S.; Abramian, P.; Abramsky, A.; Aguirre, A.; Albrecht, C.; Alou, P.; Altarelli, M.; Altmann, P.; Amyan, K.; et al. A MHz-repetition-rate hard X-ray free-electron laser driven by a superconducting linear accelerator. Nat. Photon 2020, 14, 391-397. [CrossRef]

4. Voellmer, G.M.; Jackson, M.; Shirron, P.J.; Tuttle, J.G. A cryogenic insulating suspension system for the high-resolution airbourne wideband camera (HAWC) and submillimeter and the far-infrared experiment (SAFIRE) adiabatic demagnetization refrigerators (ADRs). Astron. Telesc. Instrum. 2003, 4850, 1070-1079. [CrossRef]

5. Schaffer, D.; Nucciotti, A.; Alessandria, F. The Cryostat of the CUORE Project, a 1-ton Scale Cryogenic Experiment for Neutrinoless Double Beta Decay Research. J. Phys. Conf. Ser. 2009, 150, 1002. [CrossRef]

6. Duband, L.; Hui, L.; Lange, A. Thermal isolation of large loads at low temperature using Kevlar rope. Cryogenics 1993, 33, 643-647. [CrossRef]

7. Bersani, A.; Canonica, L.; Cariello, M.; Cereseto, R.; Di Domizio, S.; Pallavicini, M. Long term elongation of Kevlar-49 single fiber at low temperature. Cryogenics 2013, 54, 50-53. [CrossRef]

8. Eisel, T.; Kauschke, M.; Schroeder, C.; Streicher, B.; Szeligowska, A.; Walter, F.; Kollmus, H. Mass Flow Reduction by a Heater-Capillary Combination for the Cryogenic System of SIS100 at FAIR. In Proceedings of the 14th IRR International Conference Cryogenics, Dresden, Germany, 15-19 May 2017.

9. Karasev, Y.V.; Potanina, L.V.; Salunin, N.I.; Pantsyrny, V.I.; Gubkin, I.N.; Malchenkov, A.V.; Polikarpova, M.V.; Abdyukhanov, I.M.; Voloshin, I.F.; Kalinov, A. Study of Low Loss Experimental Superconducting Nb-Ti Wires to be used in FAIR Magnets. IEEE Trans. Appl. Supercond. 2015, 25, 1-5. [CrossRef]

10. Tomków, Ł.; Cholewiński, M.; Ciszek, M.; Chorowski, M. Numerical assessment of thermal behaviour of a superconducting bus-bar with a Nuclotron-type cable. Arch. Electr. Eng. 2020, 69. [CrossRef]

11. Fydrych, J. Cryogenic Transfer Lines. In Cryostat Design; Springer: Cham, Swizerland, 2016; pp. $241-274$.

12. Spiller, P.J.; Blell, U.; Boine-Frankenheim, O.; Bozyk, L.; Fischer, E.; Floch, E.; Klaus, A. Status of the SIS100 heavy ion synchrotron project at FAIR. In Proceedings of the IPAC 2013, THPWO011, Shanghai, China, 12-17 May 2013; pp. 9-11.

13. Tomków, Ł.; Trojanowski, S.; Ciszek, M.; Chorowski, M. Heat generation by eddy currents in a shell of superconducting bus-bars for SIS100 particle accelerator at FAIR. Arch. Electr. Eng. 2017, 66, 705-715. [CrossRef]

14. Tomków, Ł.; Trojanowski, S.; Ciszek, M.; Chorowski, M. Calculation of inductances and induced currents in cryogenic by-pass line for SIS100 particle accelerator at FAIR. Arch. Electr. Eng. 2019, 68, 485-496. 
15. Ventura, G.; Martelli, V. Thermal conductivity of Kevlar 49 between 7 and 290 K. Cryogenics 2009, 49, $735-737$. [CrossRef]

16. NIST Standard Reference Simulation Website, Cryogenic Technologies Group. Available online: https: //trc.nist.gov/cryogenics/materials/materialproperties.htm (accessed on 7 October 2020).

17. Eisel, T.; Chorowski, M.; Iluk, A.; Kauschke, M.; Kollmus, H.; Malcher, K.; Polinski, J.; Streicher, B. Local Cryogenics for the SIS100 at FAIR. IOP Conference Series: Materials Science and Engineering, Advances in Cryogenic Engineering. In Proceedings of the Cryogenic Engineering Conference (CEC) 2015, Tucson, AZ, USA, 28 June-2 July 2015; Volume 101.

Publisher's Note: MDPI stays neutral with regard to jurisdictional claims in published maps and institutional affiliations.

(C) 2020 by the authors. Licensee MDPI, Basel, Switzerland. This article is an open access article distributed under the terms and conditions of the Creative Commons Attribution (CC BY) license (http://creativecommons.org/licenses/by/4.0/). 